Actes de la journée d'études doctorales en histoire des techniques (8 mars 2004)

\title{
Bruno Jacomy et Michel Letté, Des techniques et des hommes : L'histoire à la lumière du présent
}

Paris, La documentation photographique, 2005, 63 pages.

Cyrille Foasso

\section{OpenEdition \\ Journals}

\section{Édition électronique}

URL : http://journals.openedition.org/dht/1131

DOI : 10.4000/dht. 1131

ISSN : $1775-4194$

\section{Éditeur :}

Centre d'histoire des techniques et de l'environnement du Cnam (CDHTE-Cnam), Société des élèves du CDHTE-Cnam

\section{Édition imprimée}

Date de publication : 1 décembre 2007

Pagination : 149-150

ISBN : 978-2-9530779-0-2

ISSN : 0417-8726

Référence électronique

Cyrille Foasso, «Bruno Jacomy et Michel Letté, Des techniques et des hommes : L'histoire à la lumière du présent ", Documents pour I'histoire des techniques [En ligne], 14 | $2^{\mathrm{e}}$ semestre 2007, mis en ligne le 03 novembre 2010, consulté le 21 septembre 2020. URL : http://journals.openedition.org/dht/1131 DOI : https://doi.org/10.4000/dht.1131

Ce document a été généré automatiquement le 21 septembre 2020.

(c) Tous droits réservés 


\title{
Bruno Jacomy et Michel Letté, Des techniques et des hommes : L'histoire à la lumière du présent
}

Paris, La documentation photographique, 2005, 63 pages.

\author{
Cyrille Foasso
}

\section{RÉFÉRENCE}

Bruno Jacomy et Michel Letté, Des techniques et des hommes : L'histoire à la lumière du présent, Paris, La documentation photographique, 2005, 63 pages.

1 Si la technique est omniprésente dans les sociétés humaines - l'homme a transformé son environnement et s'est transformé par la technique - l'histoire des techniques demeure grandement ignorée, un monde à l'écart de la culture littéraire, artistique et même scientifique. Or les développements techniques, porteurs d'avancées matérielles pour nos sociétés, sont aujourd'hui mis en question et certains s'interrogent sur les risques qu'elles font encourir à la santé, l'environnement, voire aux générations futures. Bref, les techniques sont entrées au cœur du débat public.

2 C'est pour faire le point sur ces questions que la Documentation photographique a fait appel à deux historiens des techniques, Bruno Jacomy et Michel Letté, respectivement directeur adjoint et maître de conférences du Musée des arts et Métiers - CNAM (le premier est, depuis la parution de l'ouvrage, directeur adjoint et conservateur en chef au Museum Musée des confluences de Lyon).

Le dossier s'ouvre par une grande introduction de Michel Letté qui rappelle au travers de nombreux exemples et références comment la technique est inscrite dans la culture; il résume ensuite les questions que soulèvent les historiens des techniques, avant de conclure sur les questions d'éthique et de démocratie que posent les développements scientifiques et techniques contemporains. 
4 Le dossier n'entend pas proposer un exposé chronologique sur l'histoire des techniques mais invite à la réflexion sur les relations qu'entretiennent les hommes avec les techniques, au travers d'une vingtaine de thèmes articulés en quatre grands chapitres : " des techniques pour agir et produire »; « les techniques comme mode d'appréhension du réel »; «les techniques comme support de l'échange et de la communication»; « techniques et société ».

5 On retrouve avec plaisir la griffe de Bruno Jacomy dans les thèmes qu'il a choisi de présenter, celle qui a présidé à la structuration du musée des arts et métiers en grands domaines (instruments scientifiques; matériaux; construction; communication; énergie; mécanique; transport), ou de son Histoire des techniques. Son approche culturelle des objets techniques qui s'attache à montrer les liens qui unissent les techniques et les pratiques sociales trouve dans ce dossier un format rêvé. Chacun des thèmes - « saisir et manier l'outil », « construire », « cultiver les sols », « organiser la production", «mesurer ", " découvrir le monde ", « explorer les infinis », « inventer pour innover ", "calculer », " inscrire le contenu et transmettre », " vaincre le temps et l'espace », « l'audiovisuel, ses techniques et ses publics » - se décline comme la visite d'un musée idéal, où iconographie et commentaire s'enrichissent l'un l'autre, la beauté de l'image appelant la lecture du texte, celui-ci invitant le lecteur à une observation plus approfondie et d'autant plus émerveillée des reproductions d'objet, dessin, tableau ou photographie.

6 Les contributions de Michel Letté fonctionnent plus sur l'analogie iconographique pour questionner le sens des techniques ("s'inspirer du monde animal», "l'hommemachine ", « synthétiser et copier la matière », « interpréter et restituer », « modéliser la réalité ", "vivre en réseau»). À la lumière des préoccupations les plus contemporaines quant aux effets des techniques sur le devenir de l'homme, il soulève les enjeux démocratiques du contrôle des développements techniques par les citoyens dans les textes du chapitre "techniques et société »: "interagir sur la biosphère ", "énergie et systèmes techniques", "violence et techniques", "aux risques des techniques ", « maîtriser le vivant ».

7 L'ensemble constitue donc un beau dossier à l'usage d'un large public: d'une lecture agréable, agrémentée de magnifiques images, chaque article nous entraîne dans un petit voyage à travers le temps et l'espace, les références et extraits de quelques textes majeurs de penseurs des techniques permettant en outre d'orienter vers des sources plus érudites le lecteur cherchant à approfondir sa réflexion.

8 Car si, comme il est souligné à de nombreuses reprises dans le dossier, les choix techniques ne doivent pas être le fait des seuls techniciens, hommes politiques ou industriels, il est nécessaire que les citoyens disposent d'une véritable culture scientifique et technique pour appréhender les enjeux du débat autour des questions techniques. Ce dossier y contribue sans nul doute. 


\section{AUTEURS}

\section{CYRILLE FOASSO}

Musée des arts et métiers 